\title{
Environmental awareness, initiatives and performance in the small- and medium-scale enterprise hotel industry of Malaysia
}

\begin{abstract}
This paper examines the environmental awareness, initiatives and performance in the Malaysia Small-and Medium-Scale Enterprise(SME) hotel industry revealing that most hotel managers actively introduce initiatives that contribute to cost savings. The main purpose of this paper aims to examine the environmental awareness, initiatives and performance in Malaysia SME hotel industry. A mixed research method was adopted involving quantitative surveys with 252 hotels in Malaysia and 11 face-to-face interviews with the selected hotel managers, facilities managers and engineers. Responses from the surveys and interviews with 252 managers show that SME hotels in Malaysia have a high level of environmental awareness. Most hoteliers actively introduce initiatives that contribute to cost savings. Initiatives including using energy conservation light bulbs, having an active system to detect/repair lacking facilities and installing water conserving fixtures are widely implemented, while programs involving using solar lawn light, recycling leftover food and reusing wastewater. Major barriers for going green include the lack of government regulations on environmental management systems (EMS), financial constraints, the lack of employees to handle EMS and the fear that environmental initiatives may negatively impact the guest's experience, especially customers who expect enjoying the luxuries services in Malaysia hotels. Lower star hotels experience more difficulties in adopting green approaches. This paper presents a single case study of Malaysia; therefore, the results in this research may have limited generalizability.
\end{abstract}

Keyword: Environmental management; Systems; Hospitality; Sustainability; Small-and MediumScale; Enterprise; EMS implementation 